\title{
A combinatorial guide to phase formation and surface passivation of tungsten titanium oxide prepared by thermal oxidation
}

\author{
Sebastian Siol ${ }^{a}{ }^{,}$, Noémie Ott ${ }^{a}$, Casey Bealla,b, Michael Stiefela ${ }^{a}$, Y. Unutulmazsoy ${ }^{a}$, Max Dö- \\ belic, S. David Tilley ${ }^{b}$, Patrik Schmutz ${ }^{a}$, Lars P.H. Jeurgens ${ }^{a}$, Claudia Cancellieria
}

aEmpa - Swiss Federal Laboratories for Materials Science and Technology,

Überlandstrasse 129, 8600 Dübendorf, Switzerland

bUniversity of Zurich, Department of Chemistry, Winterthurerstrasse 190, 8057 Zurich, Switzerland

'ETH Zurich, Ion Beam Physics, Otto-Stern-Weg 5, 8093 Zurich, Switzerland

*E-Mail: Sebastian.Siol@empa.ch

\section{Keywords:}

Thermal oxidation, Combinatorial phase screening, Surface analysis, Heterostructural alloy, Ternary oxide, Tungstate, Titania, $\mathrm{WO}_{3}, \mathrm{TiO}_{2}, \mathrm{~W}_{x} \mathrm{Ti}_{1-x} \mathrm{O}_{n}$

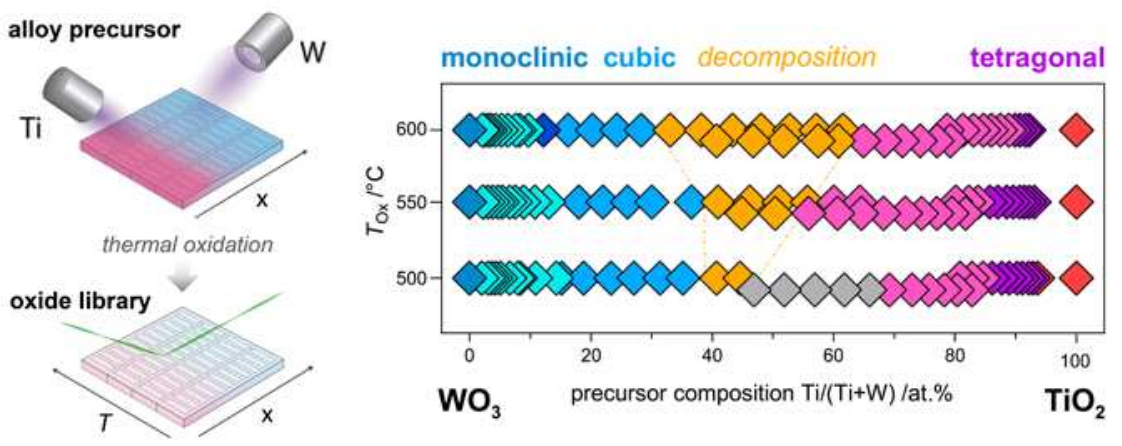

Graphical abstract: Using combinatorial thermal oxidation of solid solution $\mathrm{W}_{1-x} \mathrm{Ti}_{x}$ precursors combined with bulk and surface analysis mapping we investigate the oxide phase formation and surface passivation of tungsten titanium oxide in the entire compositional range from pure $\mathrm{WO}_{3}$ to $\mathrm{TiO}_{2}$.

This document is the accepted manuscript version of the following article:

Siol, S., ott, N., Bea11, C., Stiefe1, M., Unutulmazsoy, Y., Döbe1i, M., ... Cance11ieri, C. (2020). A combinatorial guide to phase formation and surface passivation of tungsten titanium oxide prepared by thermal oxidation. Acta Materialia, 186, 95-104. https://doi.org/10.1016/j.actamat.2019.12.026 


\begin{abstract}
:
$\mathrm{TiO}_{2}$ and $\mathrm{WO}_{3}$ are two of the most important earth-abundant electronic materials with applications in countless industries. Recently alloys of $\mathrm{WO}_{3}$ and $\mathrm{TiO}_{2}$ have been investigated leading to improvements of key performance indicators for a variety of applications ranging from photo-electrochemical water splitting to electrochromic smart windows. These positive reports and the complexity of the ternary $\mathrm{W}$-Ti-O phase diagram motivate a comprehensive experimental screening of this phase space. Using combinatorial thermal oxidation of solid solution $\mathrm{W}_{1-x} \mathrm{Ti}_{x}$ precursors combined with bulk and surface analysis mapping we investigate the oxide phase formation and surface passivation of tungsten titanium oxide in the entire compositional range from pure $\mathrm{WO}_{3}$ to $\mathrm{TiO}_{2}$. The system shows a remarkable structural transition from monoclinic over cubic to tetragonal symmetry with increasing $\mathrm{Ti}$ concentration. In addition, a strong Ti surface enrichment is observed for precursor Ticoncentrations in excess of 55 at.\%, resulting in the formation of a protective rutilestructured $\mathrm{TiO}_{2}$ surface layer. Despite the structural transitions, the optical properties of the oxide alloys remain largely unaltered demonstrating an independent control of multiple functional properties in $\mathrm{W}_{1-x} \mathrm{Ti}_{x} \mathrm{O}_{n}$. The results from this study provide valuable guidelines for future development of $\mathrm{W}_{1-x} \mathrm{Ti}_{x} \mathrm{O}_{n}$ for electronic and energy applications, but also novel engineering approaches for surface functionalization and additive manufacturing of Tibased alloys.
\end{abstract}




\section{Introduction}

$\mathrm{TiO}_{2}$ and $\mathrm{WO}_{3}$ are two of the most important earth-abundant materials for electronic and energy applications. ${ }^{1,2} \mathrm{WO}_{3}$ is commonly used in electrochromic devices ${ }^{2}$ and gas sensors ${ }^{2-}$ 4 , whereas $\mathrm{TiO}_{2}$ is employed across countless industries, including catalysis and energy conversion ${ }^{1,5-7}$. In recent years alloys of $\mathrm{WO}_{3}$ and $\mathrm{TiO}_{2}$ have been investigated ${ }^{8-10}$ leading to improvements of key performance indicators for a variety of applications. Alloying $\mathrm{WO}_{3}$ with Ti for instance has been reported to increase both electrochromic contrast and durability in smart windows ${ }^{11,12}$, whereas alloying $\mathrm{TiO}_{2}$ with $\mathrm{W}$ has been shown to improve catalytic performance ${ }^{13,14}$. Despite these promising results no comprehensive study of the $\mathrm{W}-\mathrm{Ti}-\mathrm{O}$ material system has been performed to date. This is likely rooted in the complexity of its phase diagram. The $\mathrm{TiO}_{2}-\mathrm{WO}_{3}$ alloy system is both heterostructural and heterovalent, i.e. the endmember materials exhibit different ground state structures as well as cationcoordination. At normal conditions $\mathrm{WO}_{3}$ crystallizes in the monoclinic structure although other polymorphs, including two higher symmetry tetragonal and cubic phases, have been reported ${ }^{15,16}$. The three most common (out of seven) $\mathrm{TiO}_{2}$ polymorphs are anatase, rutile, and brookite with rutile being the experimentally observed ground state ${ }^{1,17}$. In addition to this high degree of polymorphism both materials are known to form sub-stoichiometric phases, i.e. $\mathrm{TiO}_{2-x}$ and $\mathrm{WO}_{3-x}$ further increasing the number of potential phases.

The increasing demand for novel oxides with multi-property functionality however motivates the exploration of such increasingly complex material systems. Recent advances in computational materials science have played an important role in exploring previously uncharted phase space ${ }^{18}$. In an effort to accelerate the discovery and development of advanced materials computational data from first principles has been made available for many materials systems in online repositories, including $\mathrm{W}-\mathrm{Ti}-\mathrm{O}^{19}$. 


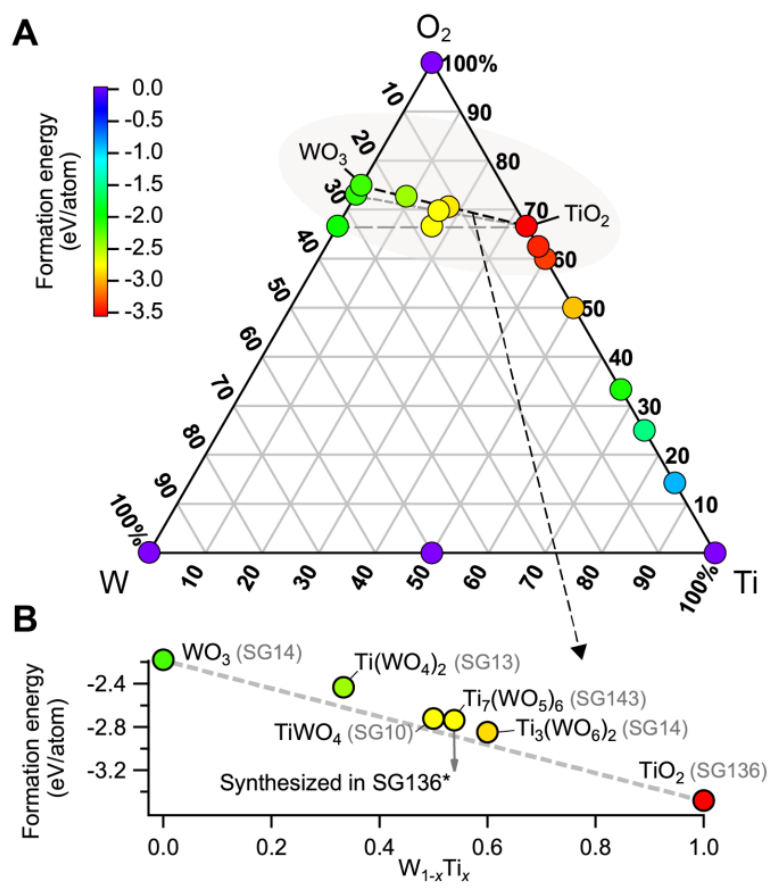

Figure 1: Calculated formation energies of compounds in the $\mathbf{W}-\mathrm{Ti}-\mathrm{O}$ system. A) Ternary phase diagram illustrating the formation energies of binary and ternary W-Ti-O compounds. Metastable and unstable compounds are included for the phase space related to this study only. B) Convex hull diagram between $\mathrm{WO}_{3}$ and $\mathrm{TiO}_{2}$ as a function of Ti concentration. *Despite being predicted to crystallize in space group (SG) 143 structure $\mathrm{Ti}_{7}\left(\mathrm{WO}_{5}\right)_{6}$ has reportedly been synthesized in SG 136 structure $^{20}$ - data from the "Materials Project" database ${ }^{19}$.

Figure 1 shows enthalpies of formation for the ternary W-Ti-O phase space including a convex hull diagram for the area of interest in this study. A number of metastable compounds are predicted close to the convex hull (Figure 1B). To our knowledge only one of the predicted ternary oxides in this $\mathrm{W}$-Ti-O phase space has been experimentally synthesized ${ }^{20}$ which further motivates an experimental screening of this system.

Recently, high-throughput combinatorial experiments have been used for an accelerated screening of synthesis-phase-diagrams in a variety of material systems ${ }^{21-25}$. This type of phase diagram screening is typically performed using non-equilibrium physical vapor deposition (PVD) techniques ${ }^{25,26}$, which often results in homogeneous alloy samples with high miscibility ${ }^{27,28}$. While this is beneficial for many applications, the non-equilibrium phase diagrams derived in these studies can be strikingly different from other synthesis techniques ${ }^{29}$; especially for oxidation from metal precursors where the oxide phase formation is often governed by the oxidation kinetics ${ }^{30,31}$. Thermal oxidation is still one of the most relevant industrial processes to produce metal oxides, in particular in sensing and catalysis due to the ability to create complex microstructures ${ }^{32}$ with large surface areas, 
which are hard to realize using PVD approaches. Despite the relevance for industrial applications, few studies combine combinatorial thermal oxidation with state of the art automated characterization ${ }^{33-35}$.

In this work we perform a comprehensive screening of the oxide phase formation and passivation of $\mathrm{W}_{1-x} \mathrm{Ti}_{x}$ precursors upon thermal oxidation. $\mathrm{W}_{1-x} \mathrm{Ti}_{x}$ solid solution precursors are thermally oxidized using a combinatorial synthesis approach coupled with automated mapping of bulk and surface properties. In the present study a particular emphasis is put on this combination of bulk and surface characterization. Many combinatorial phase mapping efforts are limited to bulk structural and compositional mapping (e.g. X-ray diffraction (XRD) combined with X-ray fluorescence (XRF)), whereas complete data sets for bulk and surface composition provide valuable information which can inform targeted tailoring of surface properties as a function of alloying concentration and synthesis parameters ${ }^{35-37}$. Using such an approach we demonstrate how oxide phase formation as well as oxide surface passivation change as a function of alloying concentration and processing temperature in tungsten titanium oxide alloys. The system undergoes a structural transition from monoclinic over cubic to tetragonal symmetry with increasing Ti content. In addition, a strong Ti surface enrichment is observed for oxide alloys grown from Ti-rich precursors, leading to the formation of protective $\mathrm{TiO}_{2}$ surface layers on top of homogeneous $\mathrm{W}_{1-x} \mathrm{Ti}_{x} \mathrm{O}_{n}$ alloys for $\mathrm{Ti}$ alloying concentrations in excess of $x>0.55$. The results of this study elucidate the phase formation and surface passivation in $\mathrm{W}_{1-x} \mathrm{Ti}_{x} \mathrm{O}_{n}$ alloys grown by thermal oxidation, but more importantly demonstrate how combinatorial synthesis coupled with bulk and surface characterization methods can provide insights in the oxidation behavior of previously underexplored material systems. 


\section{Methods}

\subsection{Synthesis}
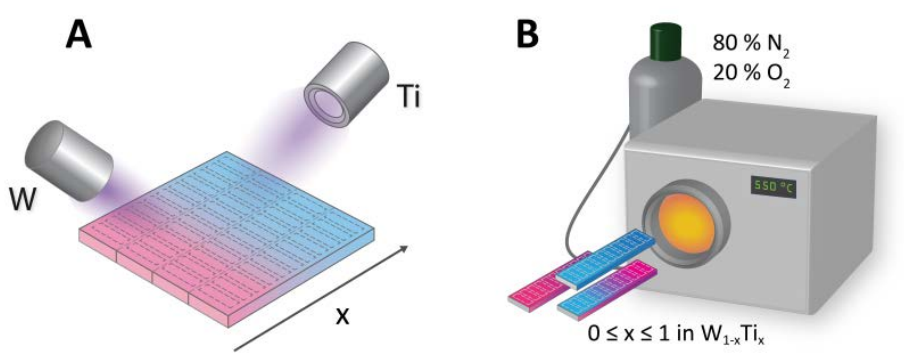

Figure 2: Combinatorial synthesis of $\mathbf{W}_{1-x} \mathrm{Ti}_{x} \mathbf{O}_{n}$ alloys: A) Metallic precursors are co-sputtered on multiple glass slides at shallow incident angles resulting in sample libraries with compositional gradients B) Ensembles of libraries, each covering the entire compositional spectrum, are thermally oxidized subsequently in a tube furnace under constant synthetic air flow $\left(80 \% \mathrm{~N}_{2}, 20 \% \mathrm{O}_{2}, \sim 200 \mathrm{ml} / \mathrm{min}\right)$ at normal pressure

The oxide alloys were produced by thermal oxidation of sputtered thin-film metallic precursors. Figure 2 illustrates the two main synthesis steps. Metallic thin film precursors were deposited on borosilicate glass slides (12.75 x $51 \mathrm{~mm}^{2}$, Eagle XG, Corning) via magnetron sputtering in an AJA 1500-F deposition chamber. The films were sputtered from metallic W and Ti targets (99.95\% purity) in pure Ar atmosphere at a process pressure of $5 \times 10^{-3} \mathrm{mbar}$ without intentional heating of the substrate. Compositional gradients were achieved by sputtering off-axis with an incident deposition angle of approximately $30^{\circ}$. No substrate rotation was used during the deposition. In order to avoid silicide formation a $15 \mathrm{~nm}$ AIN diffusion barrier was deposited prior to the $\mathrm{W}_{1-x} \mathrm{Ti}_{x}$ deposition. Due to the utilization of deposition rate gradients a slight variation in film thickness is inevitable. Precursor film thicknesses were on the order of $120 \pm 20 \mathrm{~nm}$. Each deposition run produced 4 sample libraries. Ensembles of alloy libraries covering the entire compositional range were thermally oxidized in a tube furnace under constant synthetic air flow $\left(80 \% \mathrm{~N}_{2}, 20 \% \mathrm{O}_{2}, \sim 200 \mathrm{ml} / \mathrm{min}\right)$ at atmospheric conditions. The temperature was ramped at $10 \mathrm{~K} / \mathrm{min}$ and held for $15 \mathrm{~h}$ at a constant temperature of $500{ }^{\circ} \mathrm{C}, 550{ }^{\circ} \mathrm{C}$ or $600{ }^{\circ} \mathrm{C}$, which ensured complete oxidation of the alloy precursor in the studied compositional and temperature ranges. Real-time synchrotron XRD measurements during oxidation were carried out at the material science beamline (MSX04SA) at the Swiss Light Source (SLS) in Paul Scherrer Institute (PSI), Villigen, Switzerland ${ }^{38}$. $\mathrm{W}$ and Ti films were heated in air while continuously monitoring the oxide peak intensity to determine the temperature threshold for oxide nucleation in either material (see Figure S1). While $\mathrm{W}$ already shows formation of a monoclinic oxide phase at $\sim 380^{\circ} \mathrm{C}$, Ti requires higher oxidation temperatures above $500^{\circ} \mathrm{C}$ to form a crystalline oxide. An upper temperature limit 
of $600{ }^{\circ} \mathrm{C}$ was set to minimize stress-induced cracking and delamination of the precursor layers, as well as to suppress the formation of oxygen deficient phases for the W-rich alloys ${ }^{39}$. The annealing time was chosen to be sufficient to fully oxidize Ti-rich precursors. The oxidation rate was found to be higher for W-rich alloys resulting in longer annealing times after complete oxidation. Considering that most synthesis routes are co-determined by thermodynamics and kinetics (e.g. the energy penalties associated with the creation of new interfaces for phase nucleation or decomposition, as well as the atomic mobility in the alloy and oxide systems under study), combinatorial phase screening should be directly performed with the synthesis route of interest to ensure an optimal transferability of the results. We chose thermal oxidation at moderate temperatures over other synthesis methods because of its relevance for industrial processes in the envisioned areas of application for this materials system (e.g. sensing, energy conversion and smart windows). For the electrochemical stability assessment a conductive back-contact is required. For these measurements as well as the SEM characterization a second set of samples was synthesized on single composition metal precursors. The films were oxidized for approximately $1 \mathrm{~h}$ at $600^{\circ} \mathrm{C}$ on a hot plate (BPAN-0-240-2014, Micropyretics Heaters International) in air, resulting in an oxide film on a conductive metallic back contact. The structure and surface composition of the oxides were found to closely mirror the results of the combinatorial oxidation screening.

\subsection{Characterization}

The crystal structure of the precursors as well as oxide films was studied via X-ray diffraction (XRD) using a Bruker D8 diffractometer in Bragg Brentano geometry with Cu Ka radiation and a Ni-filter. X-ray photoelectron spectroscopy (XPS) was conducted using a Physical Electronics (PHI) Quantum $2000 \mathrm{X}$-ray photoelectron spectrometer featuring monochromatic Al $\mathrm{K} \alpha$ radiation, generated from an electron beam operated at $15 \mathrm{kV}$ and $32.3 \mathrm{~W}$. The energy scale of the instrument was calibrated using $\mathrm{Au}$ and $\mathrm{Cu}$ reference samples. The analysis was conducted at $1 \times 10^{-6} \mathrm{~Pa}$, with an electron take off angle of $45^{\circ}$ and pass energies between 23.50 and $46.95 \mathrm{eV}$. Surface elemental concentrations were determined in atomic percent using the measured photoelectron peak areas after Shirley background subtraction and the built-in sensitivity factors for calculation. Charge neutralization was performed using a lowenergy electron flood gun. The photoemission spectra were aligned using the main compo- 
nent of the $\mathrm{C}$ 1s emission at $284.8 \mathrm{eV}$. X-Ray fluorescence (XRF) measurements were performed in a Bruker M4 Tornado vacuum XRF to determine the bulk composition of the specimen. The combinatorial data sets were processed and analyzed using custom written Igor Pro software routines based on the framework of COMBIgor ${ }^{40}$. The total transmittance $(T)$ was acquired using a UV-Vis-NIR spectrophotometer (Shimadzu UV-3600) equipped with an integrating sphere. The transmittance spectra were fitted using the NanoSCOPS OPTIFIT ${ }^{41}$ package (based on the Swanepoel method ${ }^{42}$ and the Sellmeier dispersion relation ${ }^{43}$ ) to estimate the effective refractive index. A Tauc analysis for an indirect transition ${ }^{44}\left((\alpha h v)^{1 / 2}\right)$ was performed to determine the optical band gap. Rutherford backscattering spectroscopy (RBS) was performed at ETH Zurich on selected samples using a $2 \mathrm{MeV}$ He beam. RUMP simulations were used to determine the film composition. The stoichiometry of the films were normalized using $\mathrm{W}+\mathrm{Ti}=1$ for alloyed and pure precursors. The microstructure and chemical composition of selected layers were characterized using conventional and scanning transmission electron microscopy (S/TEM) combined with energy-dispersive $X$-ray spectroscopy (EDS). The lamellas were prepared using a focused ion beam (FIB) (FEI Helios Nanolab 450s). Imaging was performed using a JEOL 2200FS microscope, operated at $200 \mathrm{kV}$, fitted with an on-axis bright-field (BF) detector and high-angle annular dark-field (HAADF) detector. Potentiodynamic polarization was performed in $1 \mathrm{M} \mathrm{HCl}(\mathrm{pH} \sim 0)$ and $1 \mathrm{M} \mathrm{NaOH}+1 \mathrm{M} \mathrm{NaCl}$ $(\mathrm{pH} \sim 13.5)$, representing highly acidic and alkaline environments, respectively. The potential was scanned over a wide range from open circuit potential (OCP) to $6 \mathrm{~V}_{\mathrm{Ag} / \mathrm{AgCl}}$ with a scan rate of $1 \mathrm{mV} / \mathrm{s}$. The measurements were performed using a Metrohm Autolab PGSTAT30 potentiostat. A standard $\mathrm{Ag} / \mathrm{AgCl}$ reference electrode (Metrohm, $3 \mathrm{M} \mathrm{KCl}$ ) was used as reference electrode and a Pt ring electrode was used as counter electrode. The potentials are therefore expressed versus $\mathrm{Ag} / \mathrm{AgCl}$ reference electrode (207 mV $\mathrm{SHE}_{\text {SH }}$.

\section{Results}

\subsection{Structural analysis: X-ray diffraction mapping}

Thermal oxidation of the $\mathrm{W}_{1-\mathrm{x}} \mathrm{Ti}_{\mathrm{x}}$ precursor libraries (covering the entire compositional range between pure $\mathrm{Ti}$ and pure $\mathrm{W}$ ) was combined with automated XRD mapping analysis to investigate the oxide phase constitution as function of the alloy composition and the oxidation temperature. Figure 3 provides an overview of the phase screening process for an oxidation temperature of $600{ }^{\circ} \mathrm{C}$. 


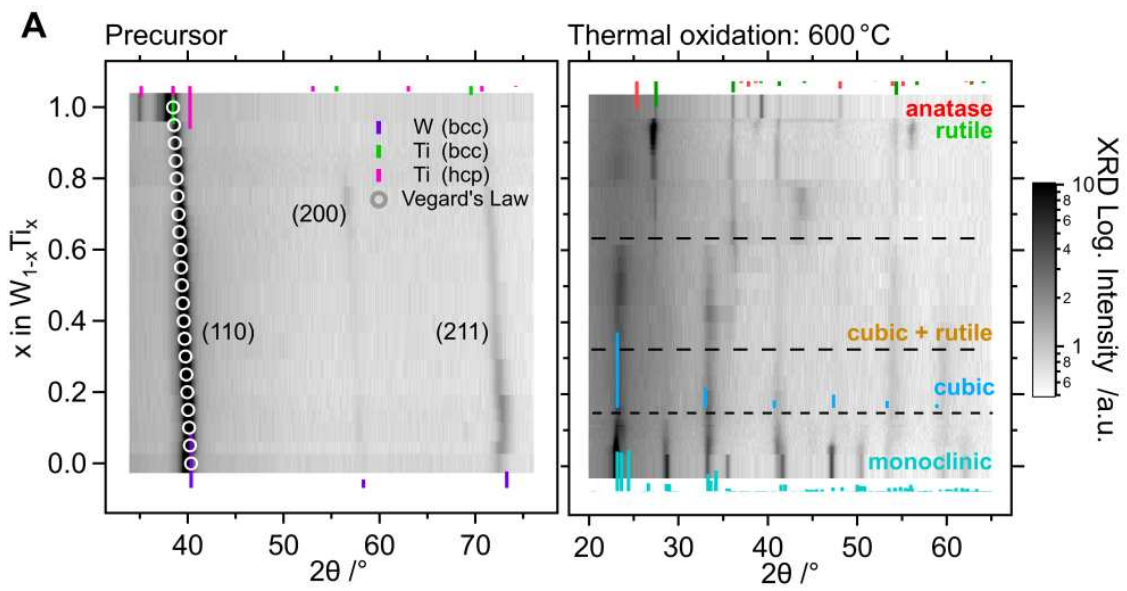

B Thermal oxidation: $600^{\circ} \mathrm{C}$

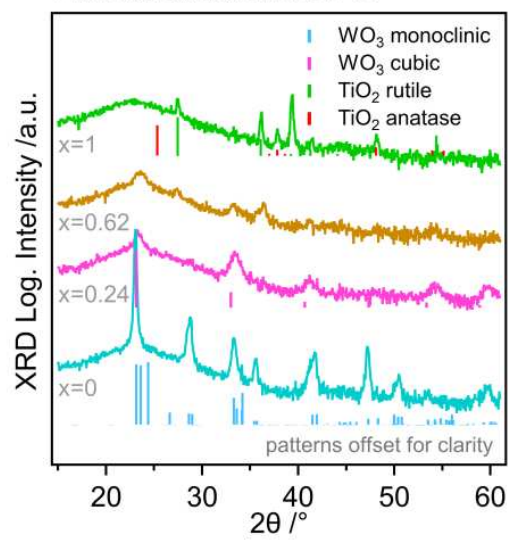

Figure 3: Structural characterization of as-deposited $\mathrm{W}_{1-\mathrm{x}} \mathrm{Ti}_{\mathrm{x}}$ precursors and their thermal oxides: $\mathrm{A}$ ) False color $\mathrm{X}$-ray diffraction maps of the as-deposited $\mathrm{W}_{1-\mathrm{x}} \mathrm{Ti}_{\mathrm{x}}$ precursors and their respective oxide product phases, as obtained after thermal oxidation at $600{ }^{\circ} \mathrm{C}$ for $15 \mathrm{~h}$. B) Conventional $2 \theta$ - display of few selected oxide diffractograms.

False color plots of the recorded XRD patterns before and after thermal oxidation are plotted as function of the $\mathrm{Ti}$ alloying concentration $x$ in Figure 3A. With the exception of pure $\mathrm{Ti}$ (hexagonal closed pack - HCP) all alloy precursors crystallize in the body centered cubic (BCC) structure. The positions of the (110) and (211) peaks shift as expected according to Vegard's Law with increasing Ti alloying concentration with no visible impurity peaks, indicating the formation of a metastable $\mathrm{W}_{1-x} \mathrm{Ti}_{x}$ solid solution for most alloying concentrations $x .{ }^{45} \mathrm{Next}$ the as-deposited alloy precursors were oxidized for 15 hours at a constant temperature in the range of $500-600^{\circ} \mathrm{C}$ and then again phase screened by XRD. With increasing $\mathrm{Ti}$ alloying concentration, the formed oxide undergoes a structural transition from monoclinic to cubic to tetragonal symmetry; a decomposition region, which shows signatures of both cubic and tetragonal phases, occurs at intermediate alloying concentrations. The individual patterns are in good agreement with reference patterns from the literature for monoclinic $\mathrm{WO}_{3}$, cubic $\mathrm{WO}_{3}$, rutile $\mathrm{TiO}_{2}$ and anatase $\mathrm{TiO}_{2}$, respectively. Representative XRD-patterns (in a conventional $2 \theta$-display), showing the principle competing oxide phases formed, are provided in Figure 3B. Slight deviations in peak position from the powder diffraction patterns are expected due to the changes in lattice constants upon alloying. The measurement procedure as outlined in Figure 3 was repeated for 3 different thermal oxidation temperatures, i.e. $500^{\circ} \mathrm{C}, 550^{\circ} \mathrm{C}$ and $600^{\circ} \mathrm{C}$. The complete results from this analysis are provided in the supporting information (Figure S2). While the same structural transition is observed for all processing temperatures, lower oxidation temperatures lead to overall reduction in crystallinity and a narrower decomposition region with improved solubility for both $\mathrm{W}$ - and 
Ti-rich alloys. In addition to a lower crystallinity observed for lower oxidation temperatures, nucleation of larger grains appears to be suppressed (broader peaks in the XRD pattern) at intermediate alloying concentration due to structural competition. Investigations of the relative position of the main XRD peaks of the oxide product phases as function of the alloying concentration show a discontinuity in the evolution of the $d$-spacing indicating solubility limits of $\sim 10$ at.\% Ti in monoclinic $(\mathrm{W}, \mathrm{Ti}) \mathrm{O}_{3-\mathrm{y}}$ as well as $\sim 10$ at.\% $\mathrm{W}$ in rutile $(\mathrm{Ti}, \mathrm{W}) \mathrm{O}_{2-\mathrm{y}}$ (see Figure S3).

\subsection{Microstructure analysis: (S)TEM and SAED}

Due to the low crystallinity of many of the grown oxide phases, the assignment of the crystallographic phases from XRD-data alone is approximate and does not adequately capture potential impurity phases, as well as vertical in-homogeneities in the oxide films. To confirm the results of the XRD screening and reveal possible in-homogeneities, cross-sectional scanning transmission electron microscopy (STEM) analysis was performed on selected oxide samples.
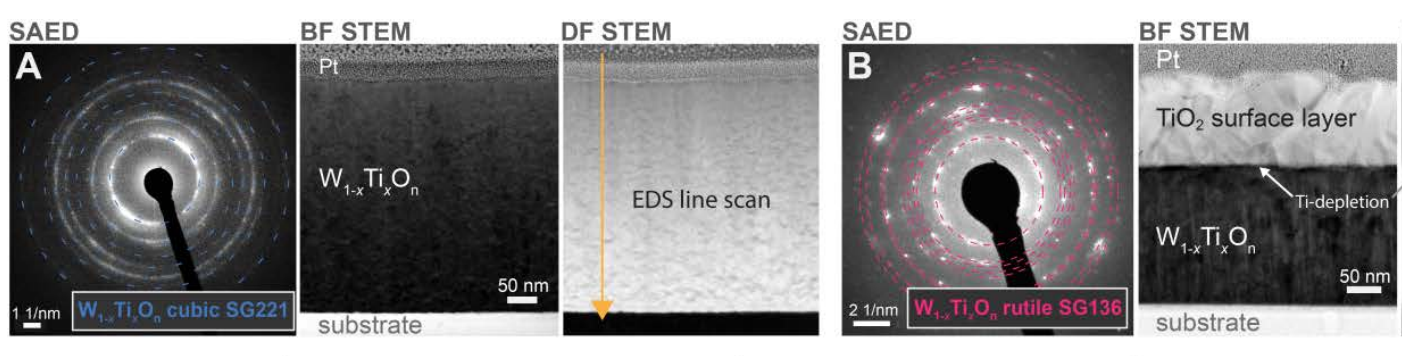
DF STEM
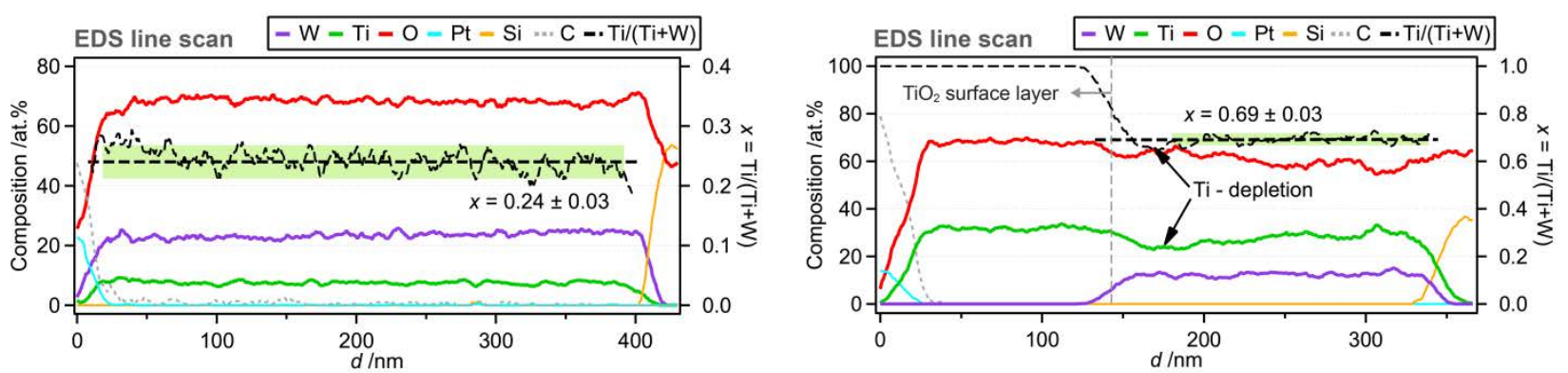

Figure 4: Microstructure of selected oxide specimens in cross-sectional view: Shown are selected area electron diffraction (SAED), bright field (BF) and dark (DF) field STEM micrographs as well as electron EDS line scans of oxides with nominal precursor compositions of $\mathrm{W}_{0.74} \mathrm{Ti}_{0.26}(\mathbf{A})$ and $\mathrm{W}_{0.28} \mathrm{Ti}_{0.72}(\mathbf{B})$, oxidized at $550{ }^{\circ} \mathrm{C}$. The oxide grown from $W_{0.74} \mathrm{Ti}_{0.26}$ crystallizes in the cubic (SG221) structure. The oxide grown from $\mathrm{W}_{0.28} \mathrm{Ti}_{0.72}$ consists of a $\mathrm{W}_{1-x} \mathrm{Ti}_{x} \mathrm{O}_{n}$ oxide alloy and a $\mathrm{TiO}_{2}$ surface layer both of which crystallize in the tetragonal rutile (SG136) structure. Only minor composition fluctuations are observed in either $\mathrm{W}_{1-\mathrm{x}} \mathrm{Ti}_{\mathrm{x}} \mathrm{O}_{\mathrm{n}}$ alloy. 
Figure 4 shows selected area electron diffraction (SAED), bright field (BF) and dark (DF) field STEM micrographs, as well as EDS line scans, of oxides grown at $550^{\circ} \mathrm{C}$ with nominal precursor compositions of $\mathrm{W}_{0.74} \mathrm{Ti}_{0.26}$ (Figure $4 \mathrm{~A}$ ) and $\mathrm{W}_{0.28} \mathrm{Ti}_{0.72}$ (Figure 4B). The SAED analysis of the oxidized $W_{0.74} T_{i} i_{26}$ alloy indicates that the formed oxide crystallizes in a primitive cubic structure (space group (SG) 223). The dark field (DF) STEM and EDS line scan analyses indicate that the oxide phase formed is structurally and compositionally rather homogenous and possesses an average composition of $\mathrm{W}_{0.76} \mathrm{Ti}_{0.24} \mathrm{O}_{2.2}$. Minor short-range fluctuations of the cation ratio in the measured EDS line scans - despite being within the experimental margin of error - could indicate an initial spinodal decomposition of the formed oxide phase at the nanometer scale. The oxide formed from the oxidation of the Ti-rich $\mathrm{W}_{0.28} \mathrm{Ti}_{0.72}$ precursor shows a strikingly different phase formation. The SAED analysis indicates the formation of an oxide phase with a tetragonal rutile structure (SG 136). However, the respective diffraction peaks show a slight asymmetry indicating the presence of two types of crystallites with different lattice parameters. This observation is confirmed by the BF and DF STEM micrographs, which clearly show the presence of two distinct layers. EDS line scans across the bi-layer structure demonstrate the formation of a $\mathrm{TiO}_{2}$ surface layer of $110 \mathrm{~nm}$ thickness on top of a homogeneous ( $\mathrm{W}, \mathrm{Ti})$-oxide phase with an average composition of $\sim \mathrm{W}_{0.31} \mathrm{Ti}_{0.69} \mathrm{O}_{1.8}$ and an average layer thickness of $170 \mathrm{~nm}$. Notably, this $\mathrm{W}_{0.31} \mathrm{Ti}_{0.69} \mathrm{O}_{1.8}$ layer exhibits a Ti-depleted region at its interface with the $\mathrm{TiO}_{2}$ surface layer (see EDS line scan and DF STEM imaging).

\subsection{Surface analysis: Photoelectron spectroscopy mapping}

XPS mapping before and after oxidation was conducted to elucidate the chemical constitutions at the alloy and oxide surfaces (note: the average XPS information depth is $<10 \mathrm{~nm}$ ). The measurements were performed over the entire alloying composition range for oxidation temperatures of $500^{\circ} \mathrm{C}, 550^{\circ} \mathrm{C}$ and $600^{\circ} \mathrm{C}$. 

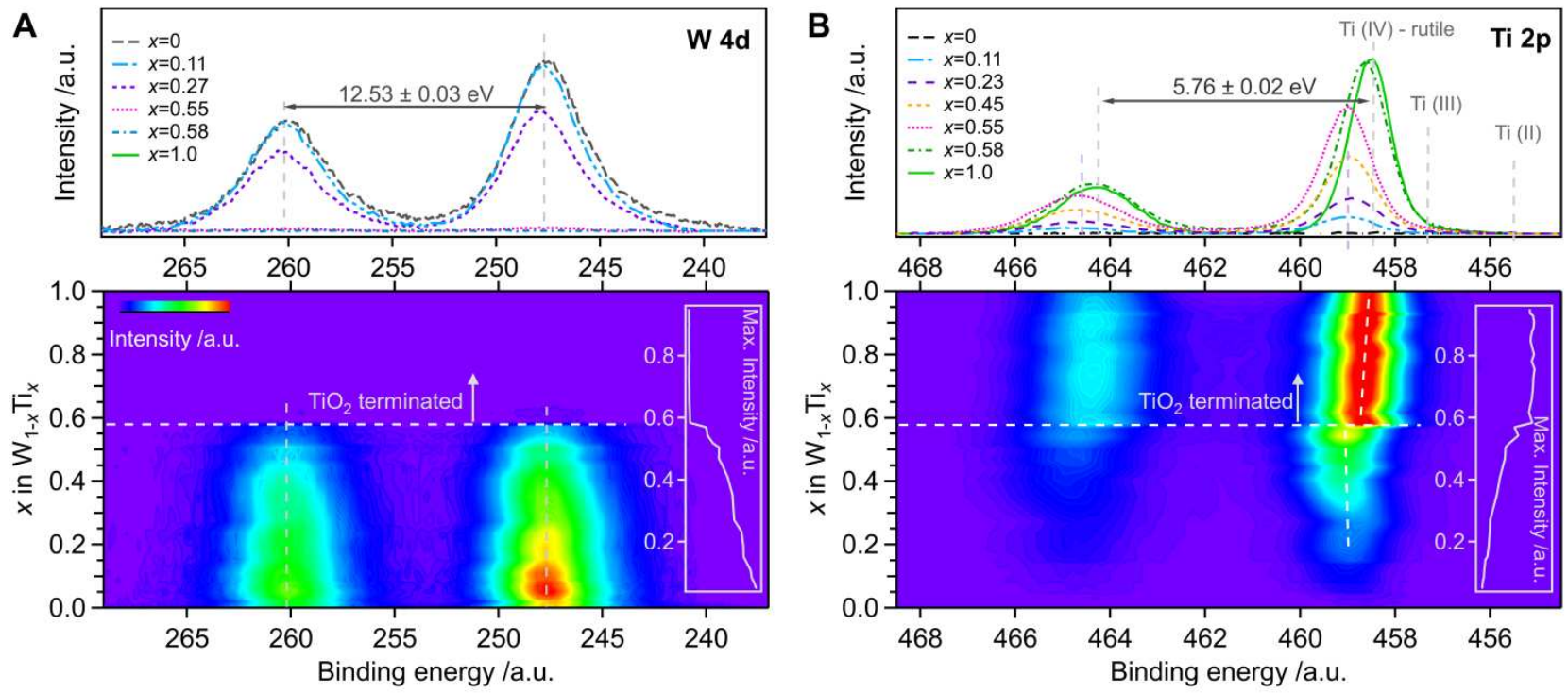

Figure 5: Photoemission spectroscopy mapping of a $\mathrm{W}_{1-\mathrm{x}} \mathrm{Ti}_{\mathrm{x}}$ precursors thermally oxidized at $500{ }^{\circ} \mathrm{C}$. Shown are false color XPS maps as function of binding energy and alloying concentration $x$, as well as detailed spectra for selected alloying concentrations. The insets show the maximum intensity over all binding energies at a given $x$. A) W 4d core level emission: No peak shift or change in chemical state is observed upon alloying. The signal is completely attenuated for alloying concentrations of $x>0.55$ B) Ti $2 p$ core level emission: Detailed spectra reveal predominantly 4 -valent Ti on the oxidized surface. For alloying concentrations of $x>0.55$ the oxides are $\mathrm{TiO}_{2}$ terminated. The dashed grey lines represent literature values from the NIST database ${ }^{46}$.

Figure 5 shows the $W 4 d$ and Ti $2 p$ core level spectra of oxides produced at $500{ }^{\circ} \mathrm{C}$, highlighting the evolution of the oxide surface chemistry as a function of alloying composition. The $\mathrm{W} 4 \mathrm{~d}$ core level is shown, rather than the more common $\mathrm{W} 4 \mathrm{f}$, since it does not overlap with the Ti $3 p$ photoemission line. For $\mathrm{W}$, no significant changes are observed as a function of alloying concentration. Both peak-shape and doublet splitting remain largely unaltered in comparison to pure $\mathrm{WO}_{3-\mathrm{x}}$, indicating the presence of $\mathrm{W}(\mathrm{VI})$ throughout. A more detailed analysis of the $\mathrm{W} 4 \mathrm{f}$ emission allows for a fitting of the $\mathrm{W}(\mathrm{V}) \mathrm{vs}$. $\mathrm{W}(\mathrm{VI})$ components (see Figure S4). $\mathrm{W}(\mathrm{V})$ is often observed in defective $\mathrm{WO}_{3-x}$ and directly correlated with the presence of oxygen vacancies ${ }^{47}$. Despite the convolution of the $W 4 f$ spectrum with the Ti $3 p$ signal and the limitations of the procedure, a general trend across all oxidation temperatures can be observed, indicating an increasing concentration of 5 -valent $\mathrm{W}$ with increasing $\mathrm{Ti}$ content. The total concentration of W(V) however stays well below $5 \%$ for all analyzed samples. Minor fluctuations in the W $4 \mathrm{~d}$ core level binding energy are present but can be explained by inaccuracies introduced during the $C 1$ s binding energy correction. The $W 4 d$ intensity decreases continuously with increasing Ti-concentration, until at a compositional threshold of 55 at.\% Ti the detected W signal disappears abruptly. The Ti $2 p$ signal on the other hand (Figure 5B) shows a strong increase in intensity at the same compositional 
threshold. The Ti $2 p$ peak position and doublet splitting for Ti-rich oxides are in good agreement with literature values for rutile $\mathrm{TiO}_{2}{ }^{46}$. At lower alloying concentrations, the $\mathrm{Ti} 2 p$ signal shifts only slightly in binding energy. The fact that the peak shape, as well as the doublet splitting, remain unaltered indicates the presence of 4-valent $\mathrm{Ti}$ in the $\mathrm{W}_{1-x} \mathrm{Ti}_{x} \mathrm{O}_{n}$ alloy accompanied by a slight change in doping. A screening of the overall oxygen concentration is in good agreement with the $\mathrm{W}$ and Ti chemical state analysis, respectively. The approximate surface oxygen to metal ratio for all investigated oxides alongside compositional data from RBS is shown in Figure S5.

\subsection{Optical spectroscopy}
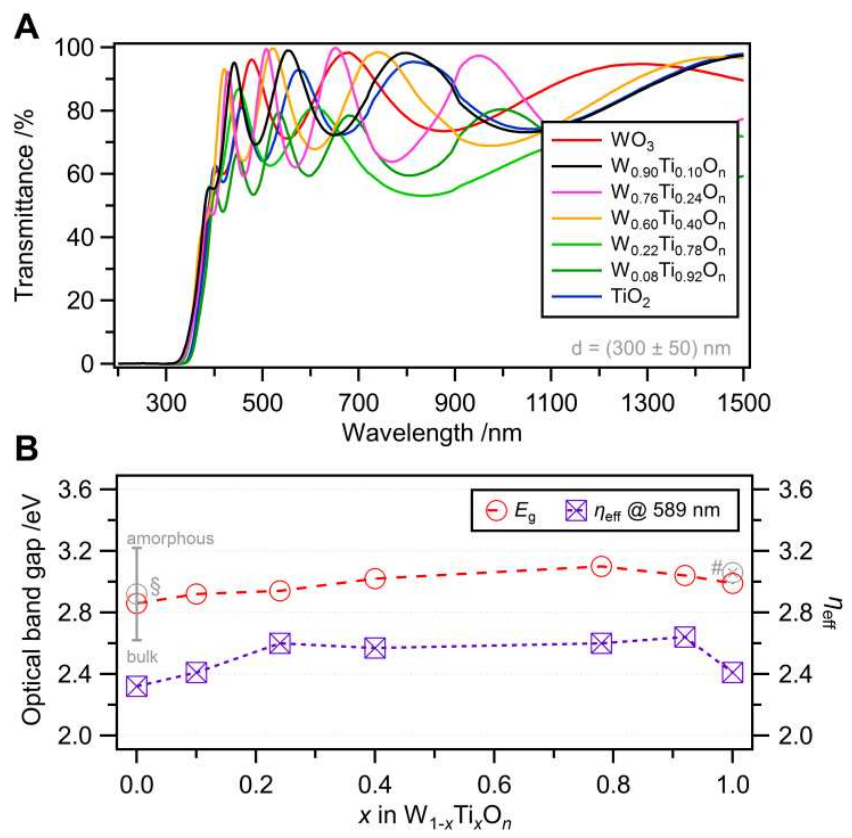

Figure 6: Optical properties of $\mathrm{W}_{1-\mathrm{x}} \mathrm{Ti}_{\mathrm{x}} \mathrm{O}_{\mathrm{n}}$ thermally oxidized at $600{ }^{\circ} \mathrm{C}$ : A) Transmission spectra for various $\mathrm{W}_{1-x} \mathrm{Ti}_{x} \mathrm{O}_{n}$ alloys oxidized at $600^{\circ} \mathrm{C}$. B) Optical band gaps and effective refraction index $\eta_{\text {eff }}$ as function of the alloying concentration. Literature values are provided for reference: $\S^{2}, \#^{48}$.

$\mathrm{W}_{1-x} \mathrm{Ti}_{x} \mathrm{O}_{n}$ alloys are particularly interesting for sustainability and energy conversion technologies. In both of these applications the optical properties are of critical importance. The optical band gap of multiple oxidized alloy precursors was investigated using UV-Vis transmission spectroscopy (Figure 6). All samples showed high transparency in the visible range of the spectrum. Figure $\mathbf{6 A}$ shows transmission spectra of different samples oxidized at $600^{\circ} \mathrm{C}$. Surprisingly, the formation of the bi-layer oxide structure does not strongly affect the optical transmission. By fitting the transmission spectrum after correcting for the substrate absorption the optical band gaps as well as the effective refractive index could be 
determined (Figure 6B). The optical band gap remains largely unaltered with a slight bowing to higher energies for alloying of $\mathrm{Ti}$ in $\mathrm{WO}_{3-x}$ as well as $\mathrm{W}$ in $\mathrm{TiO}_{2-\mathrm{x}}$. While this change can be due to a change in band structure, it can also be attributed to a general decrease in crystallinity and the resulting smaller average grain sizes for intermediate alloying concentrations, as the band gap of $\mathrm{WO}_{3}$ has been demonstrated to strongly depend on its grain size ${ }^{2}$.

\subsection{Chemical stability}
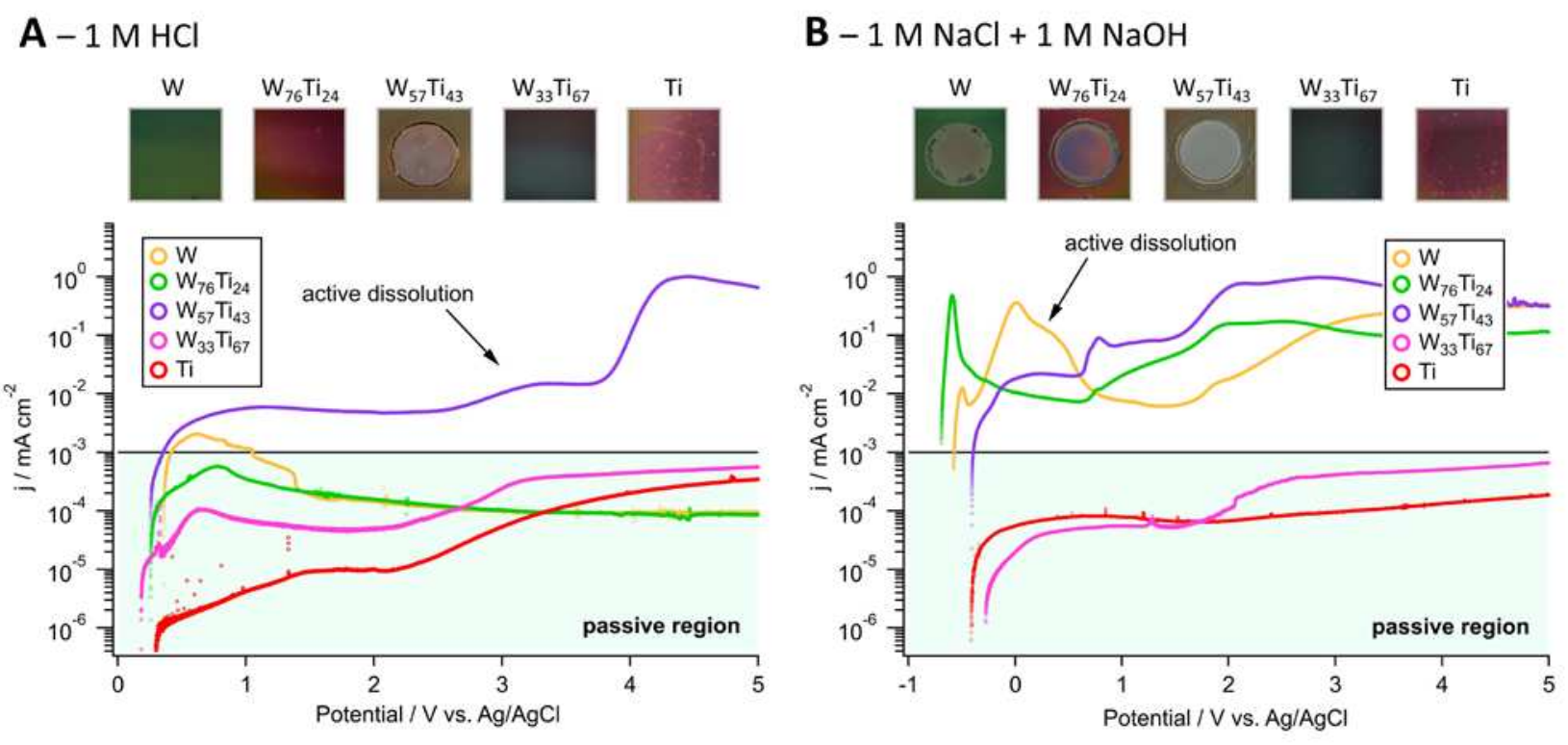

Figure 7: Potentiodynamic polarization measurements on thermal oxides grown on single composition precursors of different alloying concentration ( $1 \mathrm{mV} / \mathrm{s}$ scan rate). A) in $1 \mathrm{M} \mathrm{HCl}$ : Both $\mathrm{W}$ - and Ti-rich oxides show a passive behavior with $\mathrm{TiO}_{2}$ being the most stable, only the oxide at intermediate alloying concentration $\left(\mathrm{W}_{57} \mathrm{Ti}_{43} \mathrm{O}_{n}\right)$ undergoes active dissolution. $\left.\mathrm{B}\right)$ in $1 \mathrm{M} \mathrm{NaCl}+1 \mathrm{M} \mathrm{NaOH}$ : Oxides without a protective $\mathrm{TiO}_{2}$ surface layer are actively dissolved and fail at relatively low polarization potentials. (The shaded area highlights current densities $<1 \mu \mathrm{A} / \mathrm{cm}^{2}$ indicating passive behavior). The pictures show the respective samples after the measurements. For oxides undergoeing active dissolution the metallic substrate becomes visible.

To probe the chemical stability of the oxides and the degree of surface passivation achieved by the $\mathrm{TiO}_{2}$ surface layer, we conducted potentiodynamic polarization measurements in acidic $(1 \mathrm{M} \mathrm{HCl})$ and alkaline $(1 \mathrm{M} \mathrm{NaCl}+1 \mathrm{M} \mathrm{NaOH})$ solutions, respectively. Figure 7 shows the corresponding current density evolution of polarization curves obtained from the different thermal oxides. Single composition oxides on metallic substrates were used for this experiment. In the acidic environment, both $\mathrm{W}$-rich and Ti-rich oxides are stable, whereas the $W$-rich samples undergo a slight oxidation transition at low anodic potential. This is likely 
due to the porous microstructure (see Figure S6) and defects in the thermally grown oxide, which can result in additional oxide formation/recombination of oxygen vacancies in presence of the applied electrical potential. This oxidation current gets less pronounced with increasing Ti-alloying concentration, indicating a passivation of oxygen vacancies by inclusion of 4-valent $\mathrm{Ti}$. In acidic environment only the thermal oxide grown on $\mathrm{W}_{57} \mathrm{Ti}_{43}$ precursors undergoes active dissolution. Whereas this sample shows a comparable surface morphology to the W-rich samples (Figure S6), XRD measurements of samples in this compositional region clearly indicate decomposition and the presence of impuritiy phases (Figure $3 \mathrm{~A}$ ). At this point, it is worth mentioning that W-rich thermal oxide are chemically more stable compared to the anodic oxides investigated in our previous work. ${ }^{49}$ These anodic oxides were fully amorphous with a relatively high-density of defects, such as inclusion of impurities from the electrolyte during oxide growth. While these results indicate a detrimental effect of impurities and defects on the chemical stability, which is unrelated to the material's morphology and structure, the exact cause of the reduced stability remains unknown. In alkaline solutions $\mathrm{TiO}_{2}$ is known to be much more stable than $\mathrm{WO}_{3}$. The Ti-rich oxides $\left(\mathrm{W}_{33} \mathrm{Ti}_{67} \mathrm{O}_{\mathrm{n}}\right.$ and $\mathrm{TiO}_{2}$ ) remain passive throughout the experiment, while all tested $\mathrm{W}$-rich specimen fully dissolved already at relatively low polarization potentials. The results of the analysis are in line with the Pourbaix diagrams for pure $\mathrm{WO}_{3}$ and $\mathrm{TiO}_{2}$ and demonstrate the protective properties of the intrinsic $\mathrm{TiO}_{2}$ passivation layer in reactive environments. ${ }^{50,51}$

\section{Discussion}

\subsection{Phase evolution and surface passivation of $\mathrm{W}_{1-x} \mathrm{Ti}_{x} \mathrm{O}_{n}$ alloys}

The combination of XRF-, XRD-bulk measurements as well as XPS-mapping data provides a comprehensive image of the oxide phase formation and preferential oxidation processes in $\mathrm{W}_{1-x} \mathrm{Ti}_{x} \mathrm{O}_{n}$ alloys prepared by thermal oxidation (Figure 8). 


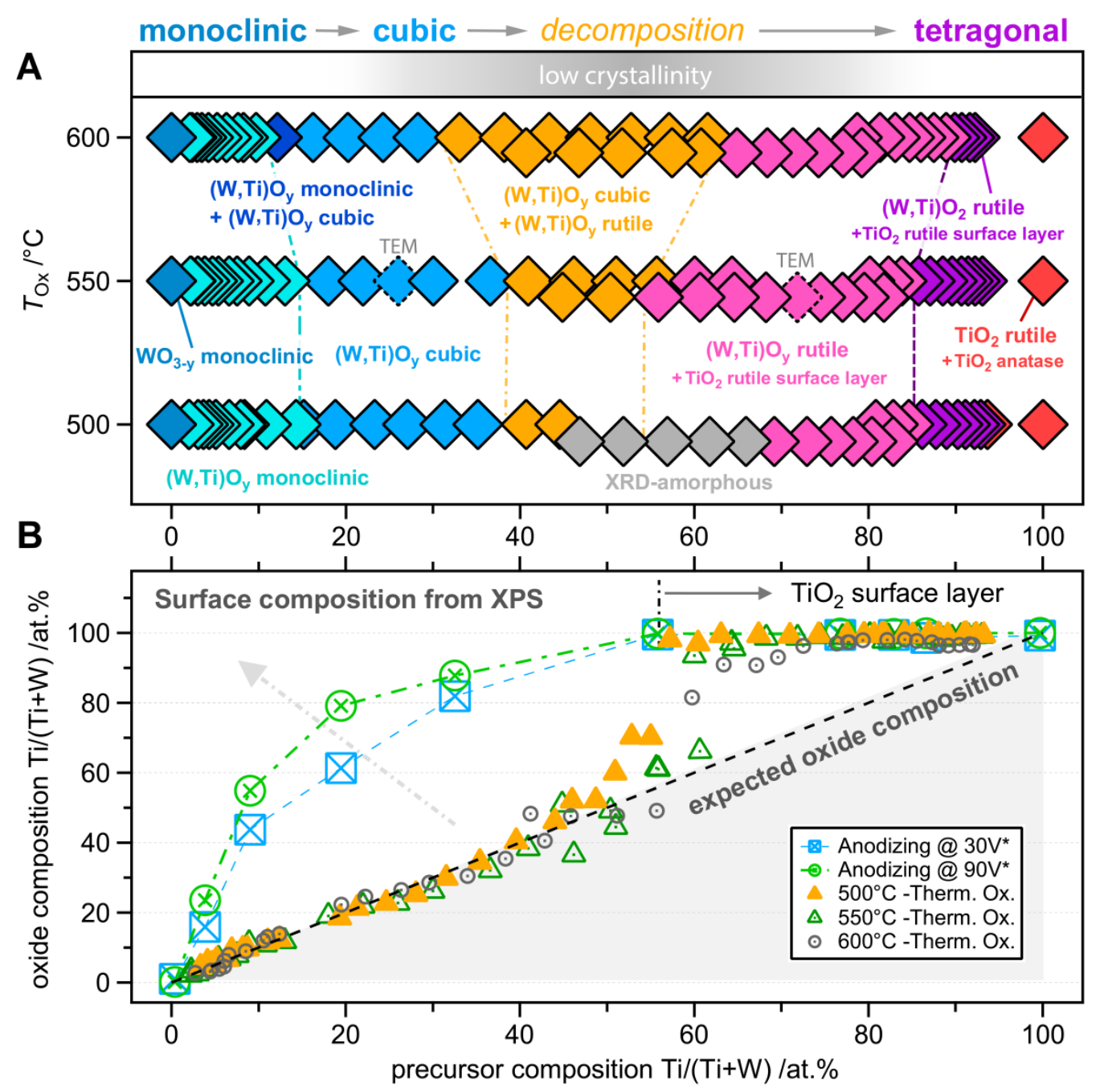

Figure 8: Structure and surface composition of $\mathrm{W}_{1-\mathrm{x}} \mathrm{Ti}_{\mathrm{x}} \mathrm{O}_{\mathrm{n}}$ thermally oxidized at different temperatures. A) The combinatorial phase map shows the predominant phases from $X$-ray diffraction measurements. A structural evolution from monoclinic to cubic to tetragonal symmetry is observed with increasing alloying concentration $x$. For intermediate $x$ a decomposition region is observed which becomes more pronounce towards higher oxidation temperatures. B) Surface cation enrichment as function of synthesis route and alloying concentration. If the surface composition equals the bulk composition, the data falls on the dotted diagonal with a slope of 1 . For alloying concentrations of $x>0.55$ the films are $\mathrm{mostly}^{\mathrm{TiO}_{2}}$ terminated. Lower oxidation temperatures provide better passivation. ${ }^{*} \mathrm{Ti}$-enrichment upon barrier anodizing from our previous work is displayed for comparison ${ }^{49}$.

Figure 8A shows the bulk oxide phase constitution as a function of the alloy precursor composition and the oxidation temperature. For low Ti concentrations monoclinic $\mathrm{WO}_{3-\mathrm{x}}$ forms. With increasing Ti concentration this phase transforms into a cubic $\mathrm{W}_{1-x} \mathrm{Ti}_{x} \mathrm{O}_{n}$ alloy (BCC) of higher symmetry. This is accompanied by a general decrease in crystallinity, which is in good agreement with previous reports in literature ${ }^{11}$. The structure of $\mathrm{WO}_{3}$ can be best described as a network of corner-sharing $\mathrm{WO}_{6}$ octahedra with a defect $\mathrm{ReO}_{3}$ structure ${ }^{2}$. The symmetry of the cubic $\mathrm{ReO}_{3}$ structure is reduced by two types of distortions: a displacement of $\mathrm{W}$ from 
the center of the octahedra and tilting of the $\mathrm{WO}_{3}$ octahedra relative to one another ${ }^{52}$. Multiple polymorphs of lower symmetry have been reported including monoclinic, hexagonal and tetragonal phases. While the monoclinic phase is generally regarded the thermodynamic ground state for $\mathrm{WO}_{3}$, an ordering of the structure can be observed upon annealing at high temperature. ${ }^{2}$ But an increase in symmetry can also be achieved by introducing static disorder to the system, either through introduction of oxygen vacancies or doping on the cation site. Depero et al. ${ }^{52}$ explained this increase in symmetry from monoclinic to cubic by a connection of cornersharing octahedra via edgesharing. Doping the material with 4-valent Ti leads to a reduction in O-content, and can facilitate this mechanism. In addition to the cubic ${ }^{11}$ phase both orthorombic ${ }^{53}$ and tetragonal ${ }^{54} \mathrm{WO}_{3}$ have been stabilized by Ti-doping.

While the grain size is generally reduced for increased Ti alloying concentrations no crystalline impurity phase is detected by XRD up to a remarkably high Ti alloying concentration of about 35 at.\%. A detailed (S)TEM analysis confirms the formation of a homogeneous $\mathrm{W}_{1-}$ ${ }_{x} \mathrm{Ti}_{x} \mathrm{O}_{n}$ phase with a cubic structure at 24 at.\% $\mathrm{Ti}$ (the measured sample is indicated in Figure $8 \mathrm{~A}$ ). Due to a convolution of the specimen's oxygen content with the glass substrate, a quantification of the bulk oxygen content with mapping techniques is challenging. However, the composition from EDS clearly indicates the formation of an oxygen deficient defect phase, which is also confirmed by RBS analysis on samples of similar composition (see Figure S5). These results are in very good agreement with the surface characterization from XPS (Figure 8B). Up to a Ti alloying content of 40 at.\%, the W/Ti atomic ratio at the oxide surface mirrors the bulk composition of the alloy precursor supporting the formation of a homogenous oxide alloy in this composition range.

The oxide phase formation for the Ti-rich side of the phase diagram looks strikingly different. As expected, oxidation of the pure Ti precursors results in the formation of $\mathrm{TiO}_{2}$ with a tetragonal rutile structure. Depending on the oxidation temperature, varying amounts of anatase traces can co-exist in the oxide; higher temperatures lead to a lower anatase phase content in the oxide. This is in good agreement with previous reports in literature. Interestingly, alloying $\mathrm{TiO}_{2}$ with $\mathrm{W}$ (as little as 5 at.\% is sufficient) stabilizes the rutile structure, even at oxidation temperatures as low as $500^{\circ} \mathrm{C}$. A similar effect has been observed by Aryanpour et al., who found that $\mathrm{W}$-doping enables the formation of $\mathrm{W}_{1-\mathrm{x}} \mathrm{Ti}_{\mathrm{x}} \mathrm{O}_{2}$ in rutile structure, while at the same time increasing the conductivity compared to pristine $\mathrm{TiO}_{2}{ }^{55}$. This is particularly 
interesting for applications in energy conversion and catalysis where the $\mathrm{W}_{1-\mathrm{x}} \mathrm{Ti}_{\mathrm{x}} \mathrm{O}_{2}$ could act as a catalyst support material. ${ }^{55}$

For Ti-concentrations in the range from 40 at.\% Ti to approximately 55 at.\% Ti, both rutile and cubic signatures is present in the diffractograms indicating a decomposition of the oxide alloys. Starting with this compositional threshold for structural decomposition, a Ti-enrichment on the surface is observed (see Figure 8B). The Ti-enrichment gets more pronounced with higher Ti concentrations and leads to a continuous $\mathrm{TiO}_{2}$ surface layer above a critical Ti alloying content of about 55 at.\%. (S)TEM analyses as well as RBS analysis of oxidized Ti-rich alloy precursors with a nominal composition of approximately $\mathrm{W}_{0.28} \mathrm{Ti}_{0.72}$ confirm the formation of a continuous $\mathrm{TiO}_{2}$ surface layer on top of a homogeneous mixed (Ti,W)-oxide phase. In addition, SAED analysis shows that both oxide layers crystallize in the rutile structure. The surface $\mathrm{TiO}_{2}$ layer increases in thickness with increasing oxidation temperature as evidenced by RBS analysis (Figure S5). To elucidate the emergence of this bi-layer structure, high temperature in-situ XRD measurements on Ti-rich alloy precursors were conducted in air (see Figure S7). After an initial peak shift of the metal peak due to O-dissolution, a mixed $(\mathrm{W}, \mathrm{Ti})$-oxide phase with a rutile structure is formed. This rutile phase stays stable up to $800{ }^{\circ} \mathrm{C}$ after which decomposition into the endmembers rutile $\mathrm{TiO}_{2-x}$ and monoclinic $\mathrm{WO}_{3-\mathrm{x}}$ Occurs. From the experimental findings presented above, a hypothesis for the underlying thermal oxidation mechanism of $\mathrm{W}_{1-x} \mathrm{Ti}_{x}$ precursors can be drawn. The onset of oxidation proceeds by the preferential oxidation of $\mathrm{Ti}$ from the $\mathrm{W}_{1-x} \mathrm{Ti}_{x}$ alloy. As a result, a surface $\mathrm{TiO}_{2}$ layer can develop for Ti alloying concentrations over 55 at.\%. The thermal oxidation of Ti metal and Ti-alloys generally follows an oxygen vacancy diffusion mechanism, which is accompanied by a continuous dissolution of $O$ from the developing oxide into the underlying alloy at the wake of the oxide growth front ${ }^{56}$. The interstitially dissolved $\mathrm{O}$ can diffuse and redistribute in the underlying alloy until the solubility product for the formation of a $\mathrm{W}_{1-x} \mathrm{Ti}_{x} \mathrm{O}_{n}$ solid solution oxide phase is locally exceeded. In this initial stage of oxide nucleation the W/Ti atomic ratio of the nucleating $\mathrm{W}_{1-x} \mathrm{Ti}_{x} \mathrm{O}_{n}$ phase will mirror the composition of the partially Ti-depleted alloy precursor. As such, a double-layered $\mathrm{TiO}_{2} / \mathrm{W}_{1-x} \mathrm{Ti}_{x} \mathrm{O}_{n}$ oxide structure can develop for $\mathrm{Ti}$ alloying concentrations over 55 at.\%. Further growth of the $\mathrm{TiO}_{2}$ overlayer then proceeds by the uptake of Ti from the underlying $\mathrm{W}_{1-x} \mathrm{Ti}_{x} \mathrm{O}_{n}$ solid solution phase, resulting in a $\mathrm{Ti}$-depletion zone in $\mathrm{W}_{1-x} \mathrm{Ti}_{x} \mathrm{O}_{n}$ layer at the interface with the $\mathrm{TiO}_{2}$ top layer. The $\mathrm{TiO}_{2}$ surface layer thickness increases towards higher oxidation temperatures due to the thermally enhanced atomic mobility of $\mathrm{Ti}$ in the developing oxide phases (see Figures 4B and 
S5). The corresponding oxidation mechanism is outlined in Figure S8. Strikingly, the $\mathrm{W}_{1-x} \mathrm{Ti}_{x} \mathrm{O}_{n}$ solid solution phase adopts a rutile structure, which should be highly metastable. This indicates that local formation of $\mathrm{WO}_{3}$ and $\mathrm{TiO}_{2}$ (as preferred by bulk thermodynamics) is kinetically hindered due to the limited atomic mobilities of $\mathrm{W}, \mathrm{Ti}$ and dissolved $\mathrm{O}$ in the alloy (for the studied temperature range up to $\left.600{ }^{\circ} \mathrm{C}\right)^{57}$. This result suggests an oxide phase evolution governed by kinetic limitations following Oswald's rule of stages ${ }^{58}$ and once more highlights the importance of conducting synthesis phase screenings specifically for the synthesis route of interest.

Figure 8B summarizes the effect of preferential oxidation on the evolving oxide surface composition as a function of alloying concentration and oxidation temperature. We recently reported on the formation of $\mathrm{TiO}_{2}$-passivated $\mathrm{W}_{1-x} \mathrm{Ti}_{x} \mathrm{O}_{n}$ oxide phases, prepared via barrier anodizing of alloy precursors ${ }^{49}$. Strikingly, the critical Ti alloying content required for the formation of a continuous and protective $\mathrm{TiO}_{2}$ surface layer is similar for both oxidation processes (i.e. anodizing vs. thermal oxidation). However, for Ti alloying contents below this critical Ti concentration, the barrier anodizing process produces a much more pronounced Ti-surface enrichment in the formed oxide phase (Figure $8 \mathrm{~B})^{49}$. During barrier anodizing a very high external electric field is applied to accelerate oxide formation on the $\mathrm{W}_{1-x} \mathrm{Ti}_{x}$ alloy, far from (local) thermodynamic equilibrium conditions, which apparently results in a relatively high Ti concentration at the developing oxide surface. On the contrary, oxide formation by thermal oxidation proceeds at a much slower rate by ionic diffusion under influence of the chemical potential gradients across the developing oxide layer, much closer to local thermodynamic equilibrium. As a result, the Ti-enrichment at the developing oxide surface during the thermal oxidation process is much less pronounced. While the oxide constitution and surface passivation strongly depend on the alloy precursor composition and the oxidation conditions, the optical properties of the material surprisingly remain largely unaltered (Figure 6), which is rooted in the similar refractive indices and band gaps for both $\mathrm{WO}_{3}$ and $\mathrm{TiO}_{2}$. This result is particularly interesting as it demonstrates the ability to independently control multiple materials properties in tungsten titanium oxide.

\subsection{Summary and conclusions}


The results of this study provide a comprehensive overview of the thermal oxidation of $\mathrm{W}_{1 \text { - }}$ $x \mathrm{Ti}_{x}$ alloys, facilitating future materials development and properties tuning in this phase space.

The system shows a strong preferential oxidation of $\mathrm{Ti}$, which results in the formation of a $\mathrm{TiO}_{2}$ surface layer for precursor compositions in excess of 55 at.\% Ti. The formation of this surface layer formation is most pronounced for intermediate alloying concentrations and correlates with the occurrence of a phase decomposition in the (W,Ti)-oxide alloys. By comparing the results with our previous work on anodic oxide formation on $\mathrm{W}_{1-x} \mathrm{Ti}_{x}{ }^{49}$, we demonstrate that the degree of preferential oxidation and surface passivation in $\mathrm{W}_{1-x} \mathrm{Ti}_{x} \mathrm{O}_{n}$ can indeed be tailored by changing the oxidation kinetics, a feature that can be used to increase the chemical stability in reactive environments. The oxide bi-layer formation on Ti-rich alloy precursors on the other hand clearly motivates a combination of bulk and surface analysis mapping for future synthesis phase diagram screenings of novel oxide alloys, in particular for the oxidation of metallic precursors or synthesis routes that include annealing steps in reactive atmospheres. Even though none of the theoretically predicted metastable ternary W-Ti-O phases were synthesized (see Figure 1), a remarkable phase transformation from monoclinic over cubic to tetragonal crystal structures is observed with increasing Ti alloying concentrations. On the W-rich side of the phase diagram, Ti-doping leads to an increase in symmetry and the stabilization of a cubic $\mathrm{W}_{1-x} \mathrm{Ti}_{x} \mathrm{O}_{n}$ phase. On the $\mathrm{TiO}_{2}$ side doping with $\mathrm{W}$ leads to a stabilization of the rutile phase upon inclusion of $\mathrm{WO}_{2}$. While the system undergoes these structural phase transitions, the optical properties remain largely unaltered, which implies that an independent control of multiple functional properties in $\mathrm{W}_{1-x} \mathrm{Ti}_{x} \mathrm{O}_{n}$ is possible.

Overall, the results of this work provide a comprehensive guide to phase formation and passivation in $\mathrm{W}_{1-x} \mathrm{Ti}_{x} \mathrm{O}_{n}$. In future work, a more detailed analysis of compositional regions of interest in the phase diagram can enable an optimization of the materials properties specific to a targeted application. While the results of this study provide valuable guidelines for future development of $\mathrm{W}_{1-x} \mathrm{Ti}_{x} \mathrm{O}_{n}$ for electronic and energy applications, they can also inform other areas of research: For instance, laser surface structuring or additive manufacturing of Ti-based alloys, for which a thorough knowledge of the surface oxide formation is beneficial. 


\section{Acknowledgements}

The authors would like to thank Mirco Chiodi for helpful discussions and assistance with the synchrotron oxidation experiments. We would like to acknowledge the Nanoscale Materials Science laboratory for access to the coating facilities as well as the MS-X04SA beamline at Swiss Light Source (SLS), PSI Villigen for providing beam time for the real-time oxidation experiments. Funding from COST project IZCNZO-174856 C16.0075, in the COST Action MP1407 (e-MINDS) is gratefully acknowledged. 


\section{References}

(1) Schneider, J.; Matsuoka, M.; Takeuchi, M.; Zhang, J.; Horiuchi, Y.; Anpo, M.; Bahnemann, D. W. Understanding TiO2 Photocatalysis: Mechanisms and Materials. Chem. Rev. 2014, 114, 9919-9986. https://doi.org/10.1021/cr5001892.

(2) Zheng, H.; Ou, J. Z.; Strano, M. S.; Kaner, R. B.; Mitchell, A.; Kalantar-Zadeh, K. Nanostructured Tungsten Oxide - Properties, Synthesis, and Applications. Adv. Funct. Mater. 2011, 21 (12), 2175-2196. https://doi.org/10.1002/adfm.201002477.

(3) Siciliano, T.; Tepore, A.; Micocci, G.; Serra, A.; Manno, D.; Filippo, E. WO3 Gas Sensors Prepared by Thermal Oxidization of Tungsten. Sensors Actuators, B Chem. 2008, 133 (1), 321-326. https://doi.org/10.1016/j.snb.2008.02.028.

(4) Shendage, S. S.; Patil, V. L.; Vanalakar, S. A.; Patil, S. P.; Harale, N. S.; Bhosale, J. L.; Kim, J. H.; Patil, P. S. Sensitive and Selective NO 2 Gas Sensor Based on WO 3 Nanoplates. Sensors Actuators, B Chem. 2017, 240 (2), 426-433. https://doi.org/10.1016/j.snb.2016.08.177.

(5) Hashimoto, K.; Irie, H.; Fujishima, A. TiO 2 Photocatalysis: A Historical Overview and Future Prospects. Jpn. J. Appl. Phys. 2005, 44 (12), 8269-8285. https://doi.org/10.1143/JJAP.44.8269.

(6) Guo, S.; Chen, X.; Hu, F.; Zhang, Q.; Liu, L. Ultralong In2S3 Nanotubes on Graphene Substrate with Enhanced Electrocatalytic Activity. ACS Appl. Mater. Interfaces 2015, 7 20164-20169. https://doi.org/10.1021/acsami.5b05519.

(7) Grätzel, M. Dye-Sensitized Solar Cells. J. Photochem. Photobiol. C Photochem. Rev. 2003, 4 (2), 145-153. https://doi.org/10.1016/S1389-5567(03)00026-1.

(8) Bendova, M.; Gispert-Guirado, F.; Hassel, A. W.; Llobet, E.; Mozalev, A. Solar Water Splitting on Porous-Alumina-Assisted TiO2-Doped WOx Nanorod Photoanodes: Paradoxes and Challenges. Nano Energy 2017, 33 (November 2016), 72-87. https://doi.org/10.1016/j.nanoen.2017.01.029.

(9) Nah, Y.-C.; Ghicov, A.; Kim, D.; Berger, S.; Schmuki, P. TiO2 -WO3 Composite Nanotubes by Alloy Anodization: Growth and Enhanced Electrochromic Properties. J. Am. Chem. Soc. 2008, 130 (48), 16154-16155. https://doi.org/10.1021/ja807106y.

(10) Kalanur, S. S.; Yoo, I.-H.; Seo, H. Fundamental Investigation of Ti Doped WO 3 Photoanode and Their Influence on Photoelectrochemical Water Splitting Activity. Electrochim. Acta 2017, 254, 348-357. https://doi.org/10.1016/j.electacta.2017.09.142.

(11) Hočevar, M.; Opara Krašovec, U. Cubic WO 3 Stabilized by Inclusion of Ti: Applicable in Photochromic Glazing. Sol. Energy Mater. Sol. Cells 2016, 154, 57-64. https://doi.org/10.1016/j.solmat.2016.04.041.

(12) Arvizu, M. A.; Triana, C. A.; Stefanov, B. I.; Granqvist, C. G.; Niklasson, G. A. Electrochromism in Sputter-Deposited W-Ti Oxide Films: Durability Enhancement Due to Ti. Sol. Energy Mater. Sol. Cells 2014, 125 (2508), 184-189. https://doi.org/10.1016/j.solmat.2014.02.037. 
(13) Sathasivam, S.; Bhachu, D. S.; Lu, Y.; Chadwick, N.; Althabaiti, S. A.; Alyoubi, A. O.; Basahel, S. N.; Carmalt, C. J.; Parkin, I. P. Tungsten Doped TiO 2 with Enhanced Photocatalytic and Optoelectrical Properties via Aerosol Assisted Chemical Vapor Deposition. Sci. Rep. 2015, 5 (April), 1-10. https://doi.org/10.1038/srep10952.

(14) Cho, I. S.; Lee, C. H.; Feng, Y.; Logar, M.; Rao, P. M.; Cai, L.; Kim, D. R.; Sinclair, R.; Zheng, $X$. Codoping Titanium Dioxide Nanowires with Tungsten and Carbon for Enhanced Photoelectrochemical Performance. Nat. Commun. 2013, 4, 1723-1728. https://doi.org/10.1038/ncomms2729.

(15) Balázsi, C.; Farkas-Jahnke, M.; Kotsis, I.; Petrás, L.; Pfeifer, J. The Observation of Cubic Tungsten Trioxide at High-Temperature Dehydration of Tungstic Acid Hydrate. Solid State lonics 2001, 141-142, 411-416. https://doi.org/10.1016/S0167-2738(01)008062.

(16) Vogt, T.; Woodward, P. M.; Hunter, B. A. The High-Temperature Phases of WO3. J. Solid State Chem. 1999, 144 (1), 209-215. https://doi.org/10.1006/jssc.1999.8173.

(17) Putatunda, A.; Singh, D. J. On the Ground State of TiO2 as Predicted by All Electron Density Functional Calculations in Relation to Experiment. Eur. Phys. J. B 2017, 90 (11), 210. https://doi.org/10.1140/epjb/e2017-80476-9.

(18) Curtarolo, S.; Hart, G. L. W.; Nardelli, M. B.; Mingo, N.; Sanvito, S.; Levy, O. The HighThroughput Highway to Computational Materials Design. Nat. Mater. 2013, 12 (3), 191-201. https://doi.org/10.1038/nmat3568.

(19) Jain, A.; Ong, S. P.; Hautier, G.; Chen, W.; Richards, W. D.; Dacek, S.; Cholia, S.; Gunter, D.; Skinner, D.; Ceder, G.; et al. Commentary: The Materials Project: A Materials Genome Approach to Accelerating Materials Innovation. APL Mater. 2013, 1 (1), 011002. https://doi.org/10.1063/1.4812323.

(20) Peters, E.; Müller-Buschbaum, H. Über Ein Niedervalentes Titan-Wolframoxid: Ti0,54W0,46O2. Zeitschrift fur Naturforsch. - Sect. B J. Chem. Sci. 1996, 51 (1), 29-31.

(21) ZHAO, J. Combinatorial Approaches as Effective Tools in the Study of Phase Diagrams and Composition-Structure-Property Relationships. Prog. Mater. Sci. 2006, 51 (5), 557-631. https://doi.org/10.1016/j.pmatsci.2005.10.001.

(22) Siol, S.; Holder, A.; Steffes, J.; Schelhas, L. T.; Stone, K. H.; Garten, L.; Perkins, J. D.; Parilla, P. A.; Toney, M. F.; Huey, B. D.; et al. Negative-Pressure Polymorphs Made by Heterostructural Alloying. Sci. Adv. 2018, 4 (4), eaaq1442. https://doi.org/10.1126/sciadv.aaq1442.

(23) Bikowski, A.; Siol, S.; Gu, J.; Holder, A.; Mangum, J. S. J. S.; Gorman, B.; Tumas, W.; Lany, S.; Zakutayev, A. Design of Metastable Tin Titanium Nitride Semiconductor Alloys. Chem. Mater. 2017, 29 (15), 6511-6517. https://doi.org/10.1021/acs.chemmater.7b02122.

(24) Bikowski, A.; Holder, A.; Peng, H.; Siol, S.; Norman, A.; Lany, S.; Zakutayev, A. Synthesis and Characterization of (Sn,Zn)O Alloys. Chem. Mater. 2016, 28 (21), 7765-7772. https://doi.org/10.1021/acs.chemmater.6b02968.

(25) Green, M. L.; Choi, C. L.; Hattrick-Simpers, J. R.; Joshi, A. M.; Takeuchi, I.; Barron, S. C.; Campo, E.; Chiang, T.; Empedocles, S.; Gregoire, J. M.; et al. Fulfilling the Promise of 
the Materials Genome Initiative with High-Throughput Experimental Methodologies. Appl. Phys. Rev. 2017, 4 (1). https://doi.org/10.1063/1.4977487.

(26) Alberi, K.; Nardelli, M. B.; Zakutayev, A.; Mitas, L.; Curtarolo, S.; Jain, A.; Fornari, M.; Marzari, N.; Takeuchi, I.; Green, M. L.; et al. The 2019 Materials by Design Roadmap. J. Phys. D. Appl. Phys. 2019, 52 (1), 013001. https://doi.org/10.1088/1361-6463/aad926.

(27) Siol, S. Accessing Metastability in Heterostructural Semiconductor Alloys. Phys. status solidi 2019, 216 (15), 1800858. https://doi.org/10.1002/pssa.201800858.

(28) Holder, A. M.; Siol, S.; Ndione, P. F.; Peng, H.; Deml, A. M.; Matthews, B. E.; Schelhas, L. T.; Toney, M. F.; Gordon, R. G.; Tumas, W.; et al. Novel Phase Diagram Behavior and Materials Design in Heterostructural Semiconductor Alloys. Sci. Adv. 2017, 3 (6), e1700270. https://doi.org/10.1126/sciadv.1700270.

(29) Siol, S.; Holder, A.; Ortiz, B. R.; Parilla, P. A.; Toberer, E.; Lany, S.; Zakutayev, A. Solubility Limits in Quaternary SnTe-Based Alloys. RSC Adv. 2017, 7 (40), 2474724753. https://doi.org/10.1039/C6RA28219A.

(30) Weller, K.; Wang, Z.; Jeurgens, L. P. H.; Mittemeijer, E. J. Thermodynamics Controls Amorphous Oxide Formation: Exclusive Formation of a Stoichiometric Amorphous (Al0.33Zr0.67)O1.83 Phase upon Thermal Oxidation of Al-Zr. Acta Mater. 2015, 94, 134-142. https://doi.org/10.1016/j.actamat.2015.04.038.

(31) RAPP, R. A. Kinetics, Microstructures and Mechanism of Internal Oxidation - Its Effect and Prevention in High Temperature Alloy Oxidation. CORROSION 1965, 21 (12), 382-401. https://doi.org/10.5006/0010-9312-21.12.382.

(32) Behera, B.; Chandra, S. Synthesis of WO 3 Nanorods by Thermal Oxidation Technique for NO 2 Gas Sensing Application. Mater. Sci. Semicond. Process. 2018, 86 (2), 79-84. https://doi.org/10.1016/j.mssp.2018.06.022.

(33) König, D.; Eberling, C.; Kieschnick, M.; Virtanen, S.; Ludwig, A. High-Throughput Investigation of the Oxidation and Phase Constitution of Thin-Film Ni-Al-Cr Materials Libraries. Adv. Eng. Mater. 2015, 17 (9), 1365-1373.

https://doi.org/10.1002/adem.201500023.

(34) Samimi, P.; Liu, Y.; Ghamarian, I.; Brice, D. A.; Collins, P. C. A New Combinatorial Approach to Assess the Influence of Alloy Composition on the Oxidation Behavior and Concurrent Oxygen-Induced Phase Transformations for Binary Ti-XCr Alloys at 650 C. Corros. Sci. 2015, 97, 150-160. https://doi.org/10.1016/j.corsci.2015.05.002.

(35) Naujoks, D.; Weiser, M.; Salomon, S.; Stein, H.; Virtanen, S.; Ludwig, A. Combinatorial Study on Phase Formation and Oxidation in the Thin Film Superalloy Subsystems CoAl-Cr and Co-Al-Cr-W. ACS Comb. Sci. 2018, 20 (11), 611-620.

https://doi.org/10.1021/acscombsci.8b00078.

(36) Siol, S.; Schulz, P.; Young, M.; Borup, K. A.; Teeter, G.; Zakutayev, A. Combinatorial In Situ Photoelectron Spectroscopy Investigation of Sb2Se3/ZnS Heterointerfaces. Adv. Mater. Interfaces 2016, 3 (24), 1600755. https://doi.org/10.1002/admi.201600755.

(37) Siol, S.; Han, Y.; Mangum, J.; Schulz, P.; Holder, A. M.; Klein, T. R.; van Hest, M. F. A. M.; Gorman, B.; Zakutayev, A. Stabilization of Wide Band-Gap p-Type Wurtzite MnTe Thin Films on Amorphous Substrates. J. Mater. Chem. C 2018, 2 (17), 3373. 
https://doi.org/10.1039/C8TC01828F.

(38) Willmott, P. R.; Meister, D.; Leake, S. J.; Lange, M.; Bergamaschi, A.; Böge, M.; Calvi, M.; Cancellieri, C.; Casati, N.; Cervellino, A.; et al. The Materials Science Beamline Upgrade at the Swiss Light Source. J. Synchrotron Radiat. 2013, 20 (5), 667-682.

https://doi.org/10.1107/s0909049513018475.

(39) Sohal, R.; Walczyk, C.; Zaumseil, P.; Wolansky, D.; Fox, A.; Tillack, B.; Müssig, H.-J.; Schroeder, T. Thermal Oxidation of Chemical Vapour Deposited Tungsten Layers on Silicon Substrates for Embedded Non-Volatile Memory Application. Thin Solid Films 2009, 517 (16), 4534-4539. https://doi.org/10.1016/j.tsf.2008.12.036.

(40) Talley, K. R.; Bauers, S. R.; Melamed, C. L.; Papac, M. C.; Heinselman, K. N.; Khan, I.; Roberts, D. M.; Jacobson, V.; Mis, A.; Brennecka, G. L.; et al. COMBIgor: Data-Analysis Package for Combinatorial Materials Science. ACS Comb. Sci. 2019, acscombsci.9b00077. https://doi.org/10.1021/acscombsci.9b00077.

(41) Alvarez, R.; Palmero, A. The software OPTIFIT v1.0 http://nanoscops.icmse.csic.es.

(42) Swanepoel, R. Determination of the Thickness and Optical Constants of Amorphous Silicon. J. Phys. E. 1983, 16 (12), 1214-1222. https://doi.org/10.1088/00223735/16/12/023.

(43) Tatian, B. Fitting Refractive-Index Data with the Sellmeier Dispersion Formula. Appl. Opt. 1984, 23 (24), 4477. https://doi.org/10.1364/AO.23.004477.

(44) Tauc, J. Optical Properties and Electronic Structure of Amorphous Ge and Si. Mater. Res. Bull. 1968, 3 (1), 37-46. https://doi.org/10.1016/0025-5408(68)90023-8.

(45) Jin, Z.; Qiu, C. Thermodynamic Evaluation of Ti-W System. Mater. Sci. Technol. 1993, 9 (5), 378-383. https://doi.org/10.1179/mst.1993.9.5.378.

(46) Naumkin, A. V.; Kraut-Vass, A.; Gaarenstroom, S. W.; Powell, C. J. NIST X-Ray Photoelectron Spectroscopy Database, Version 4.1. National Institute of Standards and Technology: Gaithersburg 2012, p http://srdata.nist.gov/xps/.

(47) Corby, S.; Francàs, L.; Selim, S.; Sachs, M.; Blackman, C.; Kafizas, A.; Durrant, J. R. Water Oxidation and Electron Extraction Kinetics in Nanostructured Tungsten Trioxide Photoanodes. J. Am. Chem. Soc. 2018, 140 (47), 16168-16177. https://doi.org/10.1021/jacs.8b08852.

(48) Pascual, J.; Camassel, J.; Mathieu, H. Fine Structure in the Intrinsic Absorption Edge of TiO2. Phys. Rev. B 1978, 18 (10), 5606-5614. https://doi.org/10.1103/PhysRevB.18.5606.

(49) Siol, S.; Beall, C.; Ott, N.; Döbeli, M.; González-Castaño, M.; Wick-Joliat, R.; Tilley, S. D.; Jeurgens, L. P. H.; Schmutz, P.; Cancellieri, C. Anodizing of Self-Passivating W x Ti 1-x Precursors for W x Ti 1- x O n Oxide Alloys with Tailored Stability. ACS Appl. Mater. Interfaces 2019, 11 (9), 9510-9518. https://doi.org/10.1021/acsami.8b19170.

(50) Lillard, R. S. The Nature of Oxide Films on Tungsten in Acidic and Alkaline Solutions. J. Electrochem. Soc. 1998, 145 (8), 2718. https://doi.org/10.1149/1.1838704.

(51) Acevedo-Peña, P.; Vazquez-Arenas, J.; Cabrera-Sierra, R.; Lartundo-Rojas, L.; González, I. Ti Anodization in Alkaline Electrolyte: The Relationship between 
Transport of Defects, Film Hydration and Composition. J. Electrochem. Soc. 2013, 160 (6), C277-C284. https://doi.org/10.1149/2.063306jes.

(52) Depero, L. E.; Groppelli, S.; Sangaletti, L.; Sberveglieri, G.; Tondello, E. Structural Studies of Tungsten - Titanium Oxide Thin Films. 1996, 387 (121), 379-387.

(53) Pecquenard, B.; Lecacheux, H.; Livage, J.; Julien, C. Orthorhombic WO3 Formed via a Ti-Stabilized WO3·1/3H2O Phase. J. Solid State Chem. 1998, 135 (1), 159-168. https://doi.org/10.1006/jssc.1997.7618.

(54) Porkodi, P.; Yegnaraman, V.; Jeyakumar, D. Polyol Mediated Synthesis of Tungsten Trioxide and Ti Doped Tungsten Trioxide. Mater. Res. Bull. 2006, 41 (8), 1476-1486. https://doi.org/10.1016/j.materresbull.2006.01.030.

(55) Aryanpour, M.; Hoffmann, R.; Disalvo, F. J. Tungsten-Doped Titanium Dioxide in the Rutile Structure: Theoretical Considerations. Chem. Mater. 2009, 21 (8), 1627-1635. https://doi.org/10.1021/cm900329k.

(56) Kofstad, P. High-Temperature Oxidation of Titanium. J. Less Common Met. 1967, 12 (6), 449-464. https://doi.org/10.1016/0022-5088(67)90017-3.

(57) Liu, Y. chang; Xu, Y.; Jeurgens, L. P. H.; Huang, Y.; Li, C.; Wang, Z. Effect of Structural Order on Oxidation Kinetics and Oxide Phase Evolution of Al-Zr Alloys. 2019, in review.

(58) Ostwald, W. Studien Über Die Bildung Und Umwandlung Fester Körper. Zeitschrift für Phys. Chemie 1897, $22 U$ (1). https://doi.org/10.1515/zpch-1897-2233. 